\title{
СОДЕРЖАНИЕ МЕДИ И ЦИНКА В СИСТЕМЕ ПОЧВА-РАСТЕНИЕ НА ПРИМЕРЕ ОКТЯБРЬСКОГО РАЙОНА ХАНТЫ-МАНСИЙСКОГО АВТОНОМНОГО ОКРУГА - ЮГРЫ
}

A.V. Sindireva, D.O. Puzanov, A.V. Bukin, E.V. Tomilova

\section{THE ASSESSMENT OF THE CONTENT OF COPPER AND ZINC IN THE SYSTEM SOIL-PLANT ON THE EXAMPLE OF OKTYABRSKY DISTRICT OF KHANTY-MANSI AUTONOMOUS AREA - YUGRA}

Синдирева Анна Владимировна - д-р биол. наук, проф. каф. геоэкологии и природопользования Тюменского государственного университета, г. Тюмень. E-mail: sindireva72@mail.ru

Пузанов Даниил Олегович - магистрант кафр. геоэкологии и природопользования Тюменского государственного университета, г. Тюмень.

E-mail: puzanov67@mail.ru

Букин Андрей Владимирович - канд. биол. наук, доц. каф. экологии и рационального природопользования Государственного аграрного университета Северного Зауралья, г. Тюмень. E-mail: 777bukin777@rambler.ru

Томилова Екатерина Владимировна - зав. лаб. агрохимии и физических свойств почв Агробиотехнологического центра Государственного аграрного университета Северного Зауралья, г. Тюмень. E-mail: 89129207657s@mail.ru

Медь и цинк являются одними из важнейших микроэлементов, принимающих участие во многих биохимических и фризиологических прочессах растений, животных и человека. Для живых организмов опасен как их избыток, так и недостаток. Цель исследования - определить содержание меди и цинка в почвах и овощных культурах территории Октябрьского района Ханть-Мансийского автономного округа - Югры. Территория исследования Октябрьский район Ханты-Мансийского автономного округа - Югры, населенные пункты: поселки Приобье, Перегребное, Уньюган и Большие Леуши. Исследования проведены в 2018-2019 ге. На данных территориях проведен отбор проб почв и произрастающих на них растений (картофель, морковь, столовая свекла). Почвы, используемые для воздельвания сельскохозяйственных культур на приуса-
Sindireva Anna Vladimirovna - Dr. Biol. Sci., Prof., Chair of Geoecology and Environmental Management, Tyumen State University, Tyumen. E-mail: sindireva72@mail.ru

Puzanov Daniil Olegovich - Magistrate Student, Chair of Geoecology and Environmental Management, Tyumen State University, Tyumen.

E-mail: puzanov67@mail.ru

Bukin Andrey Vladimirovich - Cand. Biol. Sci., Assoc. Prof., Chair of Ecology and Rational Environmental Management, Northern Trans-Urals State Agrarian University, Tyumen

E-mail: 777bukin777@rambler.ru

Tomilova Ekaterina Vladimirovna - Head, Lab. of Agrochemistry and Physical Properties of Soils, Agrobiotechnological Center, Northern TransUrals State Agrarian University, Tyumen.

E-mail:89129207657s@mail.ru

дебных участках, - агроподзолистье. Среднее содержание подвижных форм меди и цинка в исследуемых почвах характеризуется как низкое для Сu, а для Zn - оптимальное, близкое к ПДК. Значения меди в растениях изменяются в диапазоне 0,04-0,13 ме/ке. Содержание иинка составляет 0,2-0,8 мг/ке. Исходя из всех полученных данных, можно сделать вывод о дефиците меди и цинка в овощных культурах. Изучен коэфффициент биогеохимической подвижности меди и цинка, который изменяется в широких пределах от 0,01 до 0,8. Содержание меди и цинка и их биогеохимическая подвижность зависят от типа почв, биологических особенностей культуры, уровня антропогенной нагрузки в районе исследования.

Ключевые слова: медь, цинк, микроэлементы, почва, растение. 
Copper and zinc are the most important trace elements involved in many biochemical and physiological processes of plants, animals and humans. For living organisms, both their excess and lack are dangerous. The purpose of the study was to determine the content of copper and zinc in the soils and vegetable crops of the territory of Oktyabrsky district of Khanty - Mansi Autonomous Area - Yugra. The study area was Oktyabrsky district of tKhanty-Mansi Autonomous Area - Yugra, localities: Ob, Peregrebnoe, Unyugan and Bolshye Leushi. The research was conducted in 2018-2019. In these territories, soil samples were taken from homestead plots and agricultural plants (potatoes, carrots, table beets). The soils used for cultivation of agricultural crops on the homestead plots are agropodzolic. The average content of mobile forms of copper and zinc in the studied soils is characterized as low for $\mathrm{Cu}$, and optimal for $\mathrm{Zn}$ close to permissible concentration. The values of copper in plants vary in the following ranges $0.04-0.13 \mathrm{mg} / \mathrm{kg}$. Zinc content is $0.2-0.83 \mathrm{mg} / \mathrm{kg}$. Based on all the data obtained, one can make the conclusion that there is a deficit of copper and zinc in vegetable crops. The coefficient of biogeochemical mobility of copper and zinc is studied, which varies widely from 0.01 to 0.8 . The content of copper and zinc and their biogeochemical mobility depend on the type of soil, the biological characteristics of the culture, the level of anthropogenic load in the study area.

Keywords: copper, zinc, trace elements, soil, plant.

Введение. Одними из важнейших микроэлементов, необходимых для обеспечения нормального функционирования всех живых существ, являются медь и цинк. Их недостаток в объектах окружающей среды может быть причиной заболеваний растений, животных и человека. В то же время практически все микроэлементы имеют узкую грань между токсичностью и необходимостью для живых организмов [1]. Избыток доступных для растений и животных соединений цинка и меди в почве и воде может оказывать фритотоксическое и мутагенное действие, связанное с изменениями основных физиологических процессов [2, 3]. В избыточных концентрациях медь и цинк относятся к категории наиболее токсичных загрязнителей. По данным ГОСТ 14.4.1.02-083, меди присвоен второй класс опасности, цинку - первый [4].
Каждая биогеохимическая провинция характеризуется своим микроэлементным статусом. Так, в различных частях Октябрьского района ежегодные исследования территориального отдела Роспотребнадзора по ХМАО - Югре в Октябрьском районе отмечают как избыток, так и недостаток меди и цинка в поверхностных водах и почвах [5]. Из чего следует необходимость дополнительных исследований по данной проблеме. Также необходимо отметить, что комплексная оценка содержания меди и цинка в почвах и сельскохозяйственных культурах приусадебных хозяйств ранее не проводилась.

Цель исследования. Определить содержание меди и цинка в почвах и овощных культурах территории Октябрьского района ХантыМансийского автономного округа - Югры.

Объекты, условия и методы исследования. Образцы почвы и растений системно отбирались в различных частях Октябрьского административного района Ханты-Мансийского автономного округа - Югры Тюменской области. Для более полной и развернутой картины исследований были выбраны четыре населенных пункта, которые находятся в прибрежной части реки Обь. Северная часть - пос. Перегребное, центральная - г.п. Приобье, восточная пос. Большие Леуши, юго-западная - пос. Унъюган. Исследования проведены в 2018-2019 гг.

Октябрьский административный район, площадь которого составляет 24,5 тыс. км², расположен по левобережью и правобережью нижнего течения реки Обь, в западной части ХантыМансийского автономного округа - Югры Тюменской области. Его территория входит в подзону среднетаежных лесов Западно-Сибирской равнины, характеризуется ярко выраженным континентальным климатом. Октябрьский район относится к зоне рискованного земледелия, поэтому к территории для сельского хозяйства выделено 4,5 \% от всего земельного фонда района. 4,5\% поселений, 0,5 \% промышленности, 6 \% водный, 77,5 \% лес, 8 \% земли запаса и перераспределения [6]. Промышленность района представлена традиционными отраслями (лесозаготовка, лесопереработка, рыбодобыча и рыбообработка) и отраслями, история развития которых на территории Октябрьского района сравнительно небольшая (разведка недр и добыча нефти). Данный вид антропогенного воздействия может оказывать влияние на микроэлементный статус территории [7]. 
Согласно исследованиям [8], почвы и почвенный покров пахотных угодий характеризуются как пригодные для ведения очагового земледелия, возделывания картофеля, капусты, зелени (лук, укроп), моркови, свеклы. В связи с этим объектами исследования являлись почвы, используемые для возделывания сельскохозяйственных культур на приусадебных участках, агроподзолистые. На исследуемых участках также отбирали выращиваемые на них сельскохозяйственные культуры: картофрель, морковь, свекла.

Отбор проб почв на территории Октябрьского района ХМАО - Югры проводился, согласно ГОСТ 17.4.4.02-2017, методом конверта на выбранных однородных участках. Предварительный выбор участков для отбора почвенных образцов осуществлялся с помощью почвенной карты масштаба 1: 200000, по которой определялось местоположение характерных площадок для ареала распространения определенного типа почв. Выбор места для отбора почвенных образцов производился с учетом рельесра местности, экспозиции, растительного покрова. Точечные пробы отбирались пластиковым шпателем из прикопок глубиной 10-15см. Отбор расти- тельных образцов производился на тех же участках, где проводился и отбор почв. Пробоподготовка осуществлялась согласно ГОСТам $[9,10]$.

Анализ почвенных и растительных образцов $(n=60)$ проводился методом плазменной атомно-абсорбционной спектрофотометрии, в соответствии с ПНД-Ф 14.1:2:4.214-06 [11], в лаборатории агрохимии и фризических свойств почв ФГБОУ ВО ГАУ Северного Зауралья (г.Тюмень). По окончании исследований полученные данные обрабатывались статистически в програмme Microsoft Excel.

Результаты исследования и их обсуждение. Концентрация меди и цинка в почве может изменяться в зависимости от его гранулометрического состава, pH почвы, содержания органического вещества. Наиболее доступной для растений является подвижная форма Сu и Zn [12]. В связи с этим в нашей работе мы особое внимание уделили оценке содержания подвижных фрорм этих элементов.

В таблице 1 представлено содержание подвижных форм меди и цинка в почвенных образцах, которое значительно различается даже в почвах одного типа.

Таблица 1

Содержание подвижных форм Сu и Zn в почвах Октябрьского района, мг/кг сухого вещества

\begin{tabular}{|l|c|c|}
\hline \multicolumn{1}{|c|}{ Район исследования } & $\mathrm{Cu}$ & $\mathrm{Zn}$ \\
\hline Уньюган & $0,62 \pm 0,03$ & $21,05 \pm 2,5$ \\
\hline Приобье & $0,57 \pm 0,02$ & $22,53 \pm 3,0$ \\
\hline Перегребное & $0,85 \pm 0,04$ & $13,5 \pm 1,2$ \\
\hline Большие Леуши & $0,15 \pm 0,01$ & $8,15 \pm 0,9$ \\
\hline ПДК, мг/кг & 3 & 23 \\
\hline
\end{tabular}

Согласно данным таблицы 2, содержание подвижных форм меди не превышает установленных значений ПДК.

Подзолистые почвы исследуемого региона характеризуются кислой или сильнокислой реакцией, незначительным содержанием гумуса [8]. Несмотря на то что кислая реакция среды способствует увеличению подвижности тяжелых металлов, в целом в исследуемых почвах отмечается низкое содержание меди (0,57-0,85 мг/кг), что говорит о недостатке данного микроэлемента согласно приведенным в литературе градациям $[12,13]$. Самым низким значением меди среди изученных почв характеризуются дерновоподзолистые почвы, отобранные в пос. Большие Леуши $(0,15 \pm 0,01$ мг/кг сухого вещества).

В отличие от меди содержание подвижного цинка в почвах, отобранных в пос. Уньюган и Приобье, находится в районе ПДК (соответственно 21,05 22,5 и 22,53 $\pm 3,0$ мг/кг).

Концентрация тяжелых металлов в растениях прежде всего зависит от биологических особенностей культуры. Среди эдафических факторов важнейшими являются тип почвы и еe характеристики (гранулометрический состав, $\mathrm{pH}$, содержание органического веществ). И са- 
мое главное - наличие доступных (подвижных) соединений микроэлементов в почве. Поэтому особенности аккумуляции цинка и меди в почвах оказывают влияние на накопление этих микроэлементов в растениях.
В таблице 2 представлено содержание меди и цинка в овощных культурах. Данные значения содержания микроэлементов в овощных культурах, согласно градациям, представленным в литературе, характеризуются как низкие $[12,13]$.

\section{Содержание меди и цинка в овощных культурах Октябрьского района}

Таблица 2

\begin{tabular}{|c|c|c|c|c|c|}
\hline \multirow{2}{*}{$\begin{array}{c}\text { Район } \\
\text { исследования }\end{array}$} & \multirow{2}{*}{$\begin{array}{c}\text { Сельскохозяйст- } \\
\text { венная } \\
\text { культура }\end{array}$} & \multicolumn{2}{|c|}{$\begin{array}{c}\text { Среднее содержание } \\
\text { в растении, мг/кг }\end{array}$} & \multicolumn{2}{|c|}{$\begin{array}{l}\text { Коэфффициент биогеохими- } \\
\text { ческой подвижности (КБП) }\end{array}$} \\
\hline & & $\mathrm{Cu}$ & $\mathrm{Zn}$ & $\mathrm{Cu}$ & $\mathrm{Zn}$ \\
\hline Уньюган & \multirow{4}{*}{ Картофель } & 0,04 & 0,41 & 0,06 & 0,019 \\
\hline Приобье & & 0,04 & 0,31 & 0,07 & 0,014 \\
\hline Перегребное & & 0,13 & 0,32 & 0,15 & 0,024 \\
\hline Большие Леуши & & 0,10 & 0,54 & 0,67 & 0,07 \\
\hline Уньюган & \multirow{4}{*}{ Морковь } & 0,10 & 0,36 & 0,16 & 0,017 \\
\hline Приобье & & 0,05 & 0,66 & 0,09 & 0,029 \\
\hline Перегребное & & 0,10 & 0,49 & 0,12 & 0,036 \\
\hline Большие Леуши & & 0,13 & 0,51 & 0,80 & 0,063 \\
\hline Уньюган & \multirow{4}{*}{ Свекла } & 0,10 & 0,48 & 0,16 & 0,023 \\
\hline Приобье & & 0,07 & 0,83 & 0,12 & 0,037 \\
\hline Перегребное & & 0,04 & 0,21 & 0,05 & 0,016 \\
\hline Большие Леуши & & 0,07 & 0,37 & 0,47 & 0,045 \\
\hline ПДК & & 5 & 100 & & \\
\hline
\end{tabular}

Медь относится к важным микроэлементам, оказывающим значимое влияние на рост и развитие сельскохозяйственных культур. Этот элемент участвует в окислительно-восстановительных процессах, повышает интенсивность фоотосинтеза и образования хлорофиилла, способствует активизации углеводного и азотного обмена. Достаточное количество меди в сельскохозяйственных культурах улучшает сопротивляемость растений грибковым и бактериальным заболеваниям, увеличивает показатели засухо- и морозоустойчивости [2, 12, 13].

В наших исследованиях наибольшее содержание меди среди всех изучаемых культур установлено в моркови - в среднем 0,09 мг/кг. В картофреле и свекле содержание составляет в среднем 0,07 мг/кг. В целом содержание меди во всех изучаемых культурах достоверно не отличается и находится на низком уровне - 0,040,13 мг/кг, что позволяет говорить о дефиците этого микроэлемента.

На сегодняшний день доказана необходимость цинка для участия в метаболических процессах растений. Участие цинка в углеводном, фосфрорном и белковом обменах обусловлено его наличием во многих фрерментативных системах [13]. Содержание цинка в растениях составляет 0,2-0,8 мг/кг. Существенных отличий в содержании между исследуемыми культурами не выявлено. Согласно градациям, приведенным в литературе, данное количество цинка в растениях можно рассматривать как недостаточное [13-16]. В связи с этим следует предположить высокую отзывчивость овощных культур, выращиваемых на исследуемых почвах Октябрьского района, на микроудобрения, содержащие медь и цинк.

Для понимания интенсивности миграции меди и цинка в системе почва-растение установлен коэфффициент биогеохимической подвижности (КБП), который определяется как отношение содержания микроэлемента в растениях и концентрации его подвижных фрорм в почве (табл. 2). КБП зависит как от биологических особенностей культуры, так и от эдафических фракторов, а также от особенностей фризиологического действия микроэлемента. 
Согласно данным таблицы 2, КБП изменяется в широких пределах, при этом данный показатель у цинка практически на порядок ниже, чем у меди. Это объясняется более высоким содержанием подвижного цинка в почве.

В целом установлен ряд закономерностей. В каждом районе в порядке возрастания изучаемые культуры в зависимости от накопления микроэлементов составляют следующие ряды (в порядке возрастания).

Медь. Картофель - морковь (свекла) (Уньюган, дерново-подзолистые почвы).

Картофрель - морковь - свекла (Приобье, подзолистые почвы).

Свекла - морковь - картофель (Перегребное, подзолистые почвы).

Свекла - картофель - морковь (Большие Леуши, дерново-подзолистые почвы).

Цинк. Морковь - картофрель - свекла (Уньюган, дерново-подзолистые почвы).

Картофель - морковь - свекла (Приобье, подзолистые почвы).

Свекла - картофрель - морковь (Перегребное, подзолистые почвы).

Свекла - морковь - картофрель (Большие Леуши, дерново-подзолистые почвы).

Исходя из представленных данных, можно сделать вывод, что наибольшей потребностью в меди и цинке отличаются свекла и картофель. Максимальный коэфффициент биогеохимической подвижности как для цинка, так и для меди отмечается у всех изучаемых растений, произрастающих на дерново-подзолистых почвах исследуемых участков поселка Большие Леуши, что связано с низким, по сравнению с другими изучаемыми территориями, содержанием цинка и меди в почве в районе исследования. В целом содержание меди и цинка и их биогеохимическая подвижность зависят от типа почв, биологических особенностей культуры, свойств микроэлемента.

\section{Выводы}

1. Содержание подвижных форм меди и цинка в исследуемых почвах Октябрьского района ХМАО - Югры характеризуется как низкое для $\mathrm{Cu}$, а для $\mathrm{Zn}$ - оптимальное, близкое к ПДК.
2. Содержание цинка и меди в исследуемых растениях (картофель, свекла, морковь) зависит от количества подвижных форм этих элементов в почвах, от биологических особенностей культуры, фризиологической роли микроэлемента в растительном организме.

3. Изучен коэфффициент биогеохимической подвижности меди и цинка, который изменяется в широких пределах - от 0,01 до 0,8.

\section{Литература}

1. Экологическая оценка различных способов применения иодида калия под зерновые культуры / А.В. Синдирева, О.И. Курдуманова, О.В. Степанова [и др.] // Вестник КрасГАУ. 2017. № 2. С. 134-141.

2. Ермохин Ю.И., Синдирева А.В. Взаимосвязи в питании растений. Омск: ВариантОмск, 2011. 208 с.

3. Синдирева А.В. Критерии и параметры действия микроэлементов в системе почва - растение - животное: дис. ... д-ра биол. наук. Омск, 2012. 455 с.

4. ГОСТ 17.4.1.02-83 Охрана природы (ССОП). Почвы. Классификация химических веществ для контроля загрязнения. М., 1983.

5. Доклад об экологической ситуации в ХантыМансийском автономном округе - Югре в 2017 году. Ханты-Мансийск, 2019.

6. Чесноков А.Д. Охотничье-промысловые ресурсы Октябрьского района ХМАО - Югры. Киров, 2000.

7. Доклад об экологической ситуации в ХантыМансийском автономном округе - Югре в 2018 году. Ханты-Мансийск, 2019.

8. Грибов С.И. Гаськов С.И., Опрышко Н.Ф. Структуры почвенного покрова земельных угодий Ханты- Мансийского автономного округа // Вестник Алтайского государственного аграрного университета. 2004. № 4. С. 36-40.

9. ГОСТ 17.4.4.02-2017. Охрана природы. Почвы. Методы отбора и подготовки проб для химического, бактериологического, гельминтологического анализа. М., 2017.

10. ГОСТ 26929-24. Сырье и продукты пищевые. Подготовка проб. Минерализация для определения содержания токсичных элементов. М., 2017. 
11. МУ по определению тяжелых металлов в почвах сельскохозяйственных угодий и продукции растениеводства / МСХ РФ (ЦИНАО). M., 1993.

12. Kabata-Pendias A. Trace Elements in Soils and Plants / A. Kabata-Pendias. 4th Edition. Boca Raton, FL: CRC Press, 2011. 548 p.

13. Шеуджен А.Х. Биогеохимия. Майкоп: ГУРИПП «Адыгея», 2003. 1028 с.

14. Zinc application method affect agronomy traits and grain micronutrients in bread and durum wheat under zins-deficient calcareous soil / $M$. Abdoli, E. Esfandiari, B. Sadeghzadeh, S.-B. Mousavi // YYU J. Agr. Sci. 2016. № 26(2). P. 202-214.

15. Alloway B.J. Soil factors associated with zinc deficiency in crops and humans // Environ. Geochem. Helth. 2009. Vol. 31. P. 537-548.

16. Noulas C., Tziouvalekas M., T. Karyotis. Zinc in soils, water and food crops // Journal of Trace Elements in Medicine and Biology. Vol. 49. 2018. P. 252-260.

\section{Literatura}

1. Jekologicheskaja ocenka razlichnyh sposobov primenenija iodida kalija pod zernovye kul'tury / A.V. Sindireva, O.I. Kurdumanova, O.V. Stepanova [i dr.] // Vestnik KrasGAU. 2017. № 2. S. 134-141.

2. Ermohin Ju.l., Sindireva A.V. Vzaimosvjazi v pitanii rastenij. Omsk: Variant-Omsk, 2011. $208 \mathrm{~s}$.

3. Sindireva A.V. Kriterii i parametry dejstvija mikrojelementov v sisteme pochva - rastenie zhivotnoe: dis. ... d-ra biol. nauk. Omsk, 2012. $455 \mathrm{~s}$.

4. GOST 17.4.1.02-83 Ohrana prirody (SSOP). Pochvy. Klassifikacija himicheskih veshhestv dlja kontrolja zagrjaznenija. M., 1983.

5. Doklad ob jekologicheskoj situacii v HantyMansijskom avtonomnom okruge - Jugre v 2017 godu. Hanty-Mansijsk, 2019.
6. Chesnokov A.D. Ohotnich'e-promyslovye resursy Oktjabr'skogo rajona HMAO - Jugry. Kirov, 2000.

7. Doklad ob jekologicheskoj situacii $v$ HantyMansijskom avtonomnom okruge - Jugre v 2018 godu. Hanty-Mansijsk, 2019.

8. Gribov S.I. Gas'kov S.I., Opryshko N.F. Struktury pochvennogo pokrova zemel'nyh ugodij HantyMansijskogo avtonomnogo okruga // Vestnik Altajskogo gosudarstvennogo agrarnogo universiteta. 2004. № 4. S. 36-40.

9. GOST 17.4.4.02-2017. Ohrana prirody. Pochvy. Metody otbora i podgotovki prob dlja himicheskogo, bakteriologicheskogo, gel'mintologicheskogo analiza. M., 2017.

10. GOST 26929-24. Syr'e i produkty pishhevye. Podgotovka prob. Mineralizacija dlja opredelenija soderzhanija toksichnyh jelementov. M., 2017.

11. MU po opredeleniju tjazhelyh metallov $v$ pochvah sel'skohozjajstvennyh ugodij i produkcii rastenievodstva / MSH RF (CINAO). M., 1993.

12. Kabata-Pendias A. Trace Elements in Soils and Plants / A. Kabata-Pendias. 4th Edition. Boca Raton, FL: CRC Press, 2011. 548 p.

13. Sheudzhen A.H. Biogeohimija. Majkop: GURIPP «Adygeja», 2003. $1028 \mathrm{~s}$.

14. Zinc application method affect agronomy traits and grain micronutrients in bread and durum wheat under zins-deficient calcareous soil $/$ M. Abdoli, E. Esfandiari, B. Sadeghzadeh, S.-B. Mousavi // YYU J. Agr. Sci. 2016. № 26(2). P. 202-214.

15. Alloway B.J. Soil factors associated with zinc deficiency in crops and humans // Environ. Geochem. Helth. 2009. Vol. 31. P. 537-548.

16. Noulas C., Tziouvalekas M., T. Karyotis. Zinc in soils, water and food crops // Journal of Trace Elements in Medicine and Biology. Vol. 49. 2018. P. 252-260. 